\title{
Association of Risk Factors With Hepatitis B \& C Infection Among Pregnant Women Visiting a Private Tertiary Care Hospitals- Peshawar (An Un Matched Pilot Case Control Study)
}

\section{Jalwa Javed Farooqi \\ Peshawar Medical College}

Farhat Rehana Malik ( $\sim$ drfarhatmalik@gmail.com )

Associate Professor; Community Health Sciences. Peshawar Medical College, Warsak Road, Peshawar.

Riphah International University, Islamabad. Pakistan. https://orcid.org/0000-0002-5047-1754

Kanza Javed Farooqi

Peshawar Medical College

Owais Mudassar

Peshawar Medical College

\section{Research}

Keywords: Association, Hepatitis B, Hepatitis C, Risk Factors, Pakistan, Pregnancy, Prevalence

Posted Date: October 19th, 2020

DOI: https://doi.org/10.21203/rs.3.rs-92845/v1

License: (a) (i) This work is licensed under a Creative Commons Attribution 4.0 International License.

Read Full License 


\section{Abstract}

Background; Viral hepatitis causes devastating health issues to everyone globally and specifically the most vulnerable groups like pregnant ladies.

The aim of this study was to identify risk factors for hepatitis $B$ and $C$ virus infection with univariate association of virus seropositivity among pregnant women and comparison of public with private hospital data.

Study Design; An Unmatched Case Control Pilot Study.

Place and Duration; Gynaecology wards of Two Public Tertiary Care Hospitals of Peshawar and equal number of Private clinics, from September- 2018 to February- 2019.

Methods; This study enrolled 21 cases and controls as 1:1 ratio via consecutive sampling. A validated questionnaire was used. Cases included were HBsAg and ELISA positive HCV females, while anti HBsAg and Anti HCV ELISA negative were the controls. The collected data was entered and analysed in SPSS version-19. Descriptive statistics were computed by frequency and percentages while inferential statistics through Odd ratio and $95 \%$ confidence interval. P value cut of limit was set at $<0.05$.

Results; The mean age was $37 \pm 9$ for the cases and $28 \pm 6$ years for controls respectively. The risk factors with increase occurrence of disease were past history of abortion OR=1.23 (95\% Cl=0.34-4.35), past hospitalization $\mathrm{OR}=2.90(\mathrm{Cl}=0.77-10.8)$, past surgical procedure $\mathrm{OR}=3.69(\mathrm{Cl}=0.81-16.6)$, dental extraction $\mathrm{OR}=1.25(\mathrm{Cl}=0.33-4.63)$, delivery in hospital $\mathrm{OR}=4.26(\mathrm{Cl}=1.13-16.05)$, injection in hospitals $\mathrm{OR}=1.47$ $(\mathrm{Cl}=0.43-5.04)$, household contact with jaundice $\mathrm{OR}=5.66(\mathrm{Cl}=1.41-22.7)$. Normal vaginal delivery $\mathrm{OR}=1.96(\mathrm{Cl}=0.51-7.48)$ and history of sexually transmitted infections $\mathrm{OR}=2.23(\mathrm{Cl}=0.36-13.7)$ were independently associated with HBV, HCV.

Conclusion; latrogenic exposures of injections, blood transfusions, tooth extractions, home deliveries with past history of sexually transmitted infections, abortion, hepatitis infection and hospital admissions were the risk factors among the pregnant women.

\section{Plain English Summary}

This article is about a study that was conducted upon pregnant females visiting private clinics and public hospital in a populous city of a developing country. In this the researchers took 21 cases of pregnant females who were suffering from hepatitis $B$ and $C$ and compared those with 21 pregnant females suffering from diseases other than these infections. All these cases were not matched for age and other demographic characteristics so this was an unmatched case control study type.

The primary objective was to look for the causes that were responsible for these viral infections and secondly to compare the data from private and public sectors as well. 
All the cases registered were taken as frequency and then calculated percentages. The average of the pregnant females came out to be 37 years. The causes of these viral infections were having past history of abortions, past admissions in hospital, past history of having surgical procedures done, tooth extractions, having been exposed to sexually transmitted infections, exposure with a person suffering from viral hepatitis like a close contact, deliveries taken at the different places and injections taken at places either hospitals or clinics.

All the above mentioned cause were associated with these viral infections and confirmed a relationship through statistical tests performed. According to the results highest percentage was found with house hold contact of jaundice, followed by past hospitalization and having an abortion. Results revealed unhygienic injection practices at market places with unskilled deliveries and tooth extractions by quacks. All these were the factors that exposed them to these viral infections.

\section{Introduction}

"Viral Hepatitis" is an inflammation of the liver. It became the killer infection of the world in an era when HIV, tuberculosis and malaria were declining. This infection caused complex devastating health related issues with greatest disease burden. The WHO (World Health Organization) statistics claim, hepatitis related deaths to be $22 \%$ alarmingly high since 2000 . The WHO Global Hepatitis Report says hepatitis B and $C$ to be accountable for the $96 \%$ mortality worldwide ${ }^{1}$. Recent WHO statistics claims 325 million living with these common viral infections HBV (Hepatitis B Virus) and HCV (Hepatitis C Virus) globally with maximum contribution from African and East Asian countries ${ }^{2}$.

Third world, developing and poor Asian countries have faced threatening health issues from these viral infections. These can take either forms as acute, chronic and can even lead to cirrhosis and carcinomas. Pakistan have huge burden of Hepatitis B \& C, comprising of 9 and 10 million people being affected respectively with new cases as well. The new born have higher risk of infection as compared to children and adults. Needle stick injuries, intravenous drug use, blood transfusions, sexual intercourse, tattooing are main risk factors associated with these viral infections. Predominantly, use of un-sterilized instruments as well as injection contaminations are the main culprits responsible to transmit 8-16 million HBV and 2- 5 million HCV cases $^{3}$.

$\mathrm{HCV}$ prevalence rate in endemic zone of EMRO (Eastern Mediterranean Region Organization) is 2.3\% with highest burden in Pakistan as $0.3-31 \%$. Hepatitis $C$ in pregnancy is linked with the enormous risk rate of vertical transmission with high maternal complications and hepatitis in relation to neonates and foetus. It is regarded as a major contributor towards maternal deaths. Although HCV is one of the global health concern but has no vaccine, yet is treatable and has $95 \%$ cure rate. In a Pakistani study with enrolled 750 pregnant females, 44 tested positive for anti HCV antibodies, showing 5.9\% infection rate which is enormous as compared to previous Pakistani rate of $4.7 \%$ and higher than global double rate ${ }^{4}$. Recently Pakistan Medical Research Council (PMRC) survey reported prevalence of $2.5 \%$ and $4.9 \%$ in relation to HBsAg and ant- HCV infection. The risk of transmitting HCV infection from mother to baby is $3.2 \%$, 
moreover coinfection with HBV and HCV can progress to chronic condition, cirrhosis and hepatocellular carcinoma. HCV infected mothers give birth to 40, 000 children per year that end up in new 4000 infected babies. A Peshawar based study used 10, 288 pregnant females blood samples through ICT method. The study results showed HBV prevalence of $1.16 \%$ lower to previous figure of $0.34 \%$ with $1.42 \%$ of HCV rate that was much lower to earlier reported estimates ${ }^{5}$.

A Cameron based case control study of the risk factors used in vitro diagnostic test strips which were further confirmed by immunoassay kits. The prevalence of HBsAg was found to be $4.7 \%$ with significant history of contact with Hepatitis B infection and only 3.3\% were immunized against this infection. It proposed universal screening of HBsAg for all pregnant women so maternal transmission of HBV can further be reduced in their area ${ }^{6}$. Our neighbouring country Iran's case control study only described certain occupations and related risk factor's association of Hepatitis B infection through ELIZA method with revealing results of males, married, having close contact with hepatitis infection, extra marital affairs with sexual contacts, intravenous drug users, a dentist visit, phlebotomy and jobs like barbers, drivers and police independently found to be vulnerable ${ }^{7}$. Another Iranian study on the same topic showed advance age, male gender, lower social status with deficient education lead them to vulnerability of being infected with $\mathrm{HBV}^{8}$. The large number of deaths and epidemic like situations associated with hepatitis, made it customary to develop Sustainable Development Goals (SDGs) and Global Health Sector Strategy (GHSS) by World Health Organization (WHO) to reduce $90 \%$ of its incidence as well as $65 \%$ mortality thereby eliminating it by 2030. Although it seems impossible with developing countries like Pakistan but still hoping for best ${ }^{9,10}$. Antenatal screening for hepatitis although is a problematic issue yet is important to provide these facilities to reduce mother to child transmission with lowering the risks in future generations as well ${ }^{11}$.

These common viral infections Hepatitis B and C pose a life threatening complications in pregnancy. Drastically there is higher risk of transmitting these infections to their off springs, which a country depends for their future progress. Keeping in focus these aspects, this present study was drafted to get an insight about the hidden/ revealed/ apparent/ previously described / new discovery of risk factors of these viral infections. The purpose of this study was to determine prevalence, identify potential risk factors for hepatitis B and C infections, with univariate association of hepatitis B \& C virus seropositivity with potential risk factors among the pregnant females of Peshawar seeking ante natal care in Tertiary Care Hospitals and comparison of public and private hospital data in this regard.

\section{Methodology}

This unmatched pilot case control study was conducted upon 42 hepatitis $B$ and $C$ infected pregnant women admitted in Gynaecology wards of Tertiary Care Hospitals of Peshawar from September- 2018 to February- 2019.

Study approval was taken from the Institutional Review Board Committee of Prime Hospitals. Study hospitals included two public setups (Khyber Teaching and Lady Reading Hospital) and two private 
Tertiary Care Hospitals i. e Mercy and Kuwait Teaching Hospitals with equal number of private clinics.

Permission regarding the study was taken from the MS of the hospitals along with HODs of Gynaecology units. Informed written consent taken from the included women.

Total sample size $(n=42)$ was calculated through Kelsey formula through sample size online calculator with 0.05 significance level, $80 \%$ power and 1: 1 ratio for cases and controls. Out of which 21 were the cases and equal number of controls. Consecutive sampling techniques used for data collection through interviews by a validated structured questionnaire. Viral status of the pregnant women taken from their recent laboratory reports during admission.

Cases included women at any stage of pregnancy or within forty days after delivery with positive serological evidence of HCV by enzyme linked immunosorbent assay (ELISA III) or positive HBs Ag attending the study hospitals. Included controls were women at any stage of pregnancy or within 40 days after delivery with negative serological evidence of HCV by ELISA III or negative HBs Ag, attending the study hospitals. Pregnant females unable to respond to questions as well as the ones without consent were excluded from the study.

Data Analysis: All the collected data were entered in Statistical Package for Social Sciences (SPSS Version-19) for analysis. Descriptive statistics were computed for the categorical variables with frequency and percentages, however quartile analysis for the continuous variables. Univariate association of HBV and HCV infection seropositivity with the potential risk factors were calculated through linear regression with computation of Odd ratio and $95 \%$ confidence interval. P value cut of limit was set at $<0.05$.

\section{Results}

This case control study enrolled 21 cases of pregnant women with HBsAg and HCV positive along with 21 controls of negative serology. The mean $( \pm S D)$ age of cases were $37( \pm 9)$ years and $28( \pm 6)$ years for the controls.

The sero prevalence of HBV was $28.9 \%$ and HCV was $61.9 \%$ with $9.5 \%$ women co-infected with Hepatitis $\mathrm{B}$ and $\mathrm{C}$ virus. While controls were all negative for $\mathrm{HBV}$ and $\mathrm{HCV}$ but had other medical diseases.

Past obstetrical history showed that the average number of pregnancies among cases and control was 4 $( \pm 2)$. Furthermore, injection practices among the cases from a health facility was $54 \%$ whereas the controls were $45.08 \%$. Injections were being given at market places other than competent authorities by quacks.

Table 1 shows the details of the demographic characteristics of the all the study participants categorized into cases and controls. Assessments of the risk factors associated with Hepatitis B and C infections is depicted in Graph 1. Descriptive with Inferential statistical test results are shown in detail in Table 2. 


\section{Discussion}

This study evaluated risk factors of hepatitis infection among the pregnant group of females and association with the seropositivity of infection. These pregnant women had higher risk with a house hold contact, past history of admission in a hospital, past abortion and past experience of surgical intervention done. The HBV and HCV prevalence was $28.9 \%$ and $61.9 \%$ respectively with $9.5 \%$ women coinfected with both types. Hepatitis- $\mathrm{C}$ was more common among this vulnerable group, as compared with the other.

A recent Pakistani study on pregnant viral infections prevalence found hepatitis- $B$ as $1.16 \%$ with highest percentage $(1.69 \%)$ in the month of January whereas hepatitis- $\mathrm{C}$ had $1.42 \%$ with highest figures as $2.2 \%$ in the month of March in Peshawar district. Ten thousand two hundred eighty-eight pregnant women participated in this study. Although present study was not large enough to this in term of sample size plus the area, but still findings of prevalence of these infections do correlate to each other among pregnant women and same area as well ${ }^{5}$. A Cameron based study among the pregnant women found high statistics of hepatitis- $B$ infection, which is contrary to the present study findings ${ }^{6}$.

A facility based study in Ghana, described high prevalence of Hepatitis- B infection i. e 7.7\% among educated, unemployed and multiparous antenatal patients with no significant association of sociodemographic characteristics and hepatitis- B infection. This study recruitment protocols resembled the present study however they did not take into account the risk factors and their association which was explained clearly in the present study with significance as well ${ }^{12}$. A retrospective Brazilian study of hepatitis screening among pregnant women, found $1.9 \%$ and $1.3 \%$ seroprevalance of Hepatitis B and C respectively. They found no significant association of age with these viral infections among pregnant females, but a high frequency of hepatitis infection according to the results. These results are not in association with the present study and further they only took prevalence whereas risk factor evaluation was missing in their study ${ }^{13}$.

An Egyptian Case Control study of Hepatitis- B Infection calculated mean age of the study participants as 32 years and $62 \%$ males in the study contrary to the present study. Their sample size was calculated with $95 \%$ confidence interval, $80 \%$ power of the study and 1: 2 ratios among cases and controls, in association with this study. The results revealed prisons and military facilities (OR: 19.2; $\mathrm{Cl}$ 2.7-135.6) with increased risk of HBV infection; with intravenous drug users, contact with any hepatitis infected family member and invasive procedures exposures as risk factors. Multivariate analysis showed (OR: 19.2; $\mathrm{Cl} 2.7-135.6)$ in military areas; $(\mathrm{OR}=8.7 ; 95 \% \mathrm{Cl}: 1.1-72.1)$ in intravenous drug users and $(\mathrm{OR}=5.6 ; 95 \% \mathrm{Cl}: 1.1-$ 27.2) among the persons going through unsafe invasive techniques ${ }^{14}$.

A very unique study regarding status of HBV and HCV infection was studied in 306 transgender community of Rawalpindi with a mean age of 27 Years. The results showed predominance of HCV infection among the group with HBV as an insignificant infection. The ones who were going to Barbers were found to be $34.61 \% \mathrm{HCV}$ positive. Bisexuality was the factor leading to sexually transmitted 
diseases among them, number of sexual partners with frequency of sex without safe equipment, unsafe razors used for body cleaning, low budget barber shops for hair cutting, unsafe street dentists visits, poverty, stress and economic crisis were the driving forces behind higher disease burden among these groups. The present study was similar in case of both infections and risk factors evaluated in it but completely different in the group being tested so cannot be compared with each other ${ }^{15}$.

The prevalence of hepatitis - B infection only was studied among antenatal patients and showed high seropositivity of the infection, with older aged women as the most infected. No association of sociodemographic variables and risk factors identified with the infection revealed ${ }^{16}$. These findings are not in association with the present study, as both infections were studied and found significant associations of risk factors with the HBV and HCV infections. Both infections when studied among pregnant women, hepatitis- $\mathrm{B}$ was found to be in higher prevalence as compared with hepatitis- $\mathrm{C}$. Multiple sex partners $(\mathrm{OR}=11.6 ; 95 \% \mathrm{Cl}: 5.1-26.7 ; \mathrm{P}<0.001)$ was the only significant risk factor associated with hepatitis- $B$ infection, rest were not ${ }^{17}$. These findings are not correlated with present study because of the norms of an Islamic state and risk factors involved were different as well.

A retrospective analytical study among pregnant women of Swat, concluded HBV and HCV as the commonest infections with highest frequency of HCV in females. The recommended antenatal screening before delivery and surgical interventions. They compared HBV infection in urban (39.02\%) and rural (60.98\%) as well as HCV in urban $(27.40 \%)$ and rural $(72.60 \%)$, showing high seropositivity of HCV in rural sector. Although results correlate with the present study but it is a case control and with no comparison of urban and rural women. Re use of contaminated syringes, instruments and blood products were the listed risk factors, however present study revealed past history of infection, abortion and admission in hospital with any surgical intervention as risk factors ${ }^{18}$. A descriptive study upon pregnant females visiting Gynaecology and Obstetrics department of Shaikh Zayed Hospital of Lahore also concluded more frequency of $\mathrm{HCV}$ infection in multigravida and previous exposure to surgery, blood transfusion and hospital admission were the risk factors. All the findings are in association with the present study except for the case control study design ${ }^{19}$. Similarly, another Pakistani study at Karachi also revealed same high frequency of HCV infection in pregnant women and no association of any risk factors with the both infections. These findings recommended universal antenatal screening for the females, in order to lower down its burden. This study was similar to the present study in terms of frequency however sexually transmitted infections and delivery mode was found to be significant in the present study 20 .

Limitations of the study included as under;

- It was an unmatched case control study. Although study was conducted in tertiary care hospitals, but the data cannot be extrapolated.

- A selection bias can never be excluded from such studies.

- The core antibodies were not tested, that could have an effect upon the results. 


\section{Conclusion}

This study revealed latrogenic exposures of the mother to injections, blood transfusions, hospitalization and surgical procedures were the major significant risk factors for hepatitis- B \& C in pregnant women. Delivery at home by untrained person, sexually transmitted infections exposure, tooth extractions at market places and history of abortion were also associated with these viral infections.

Recommendation; In the light of the current study results, it is hereby recommended to have universal screening of Hepatitis B \& C among all antenatal females of private as well as public sector hospitals seeking health care; for prevention of not only infections among these individuals but transmission as well to their off springs.

\section{List Of Abbreviations}

HIV Human Immuno Deficiency Virus

WHO World Health Organization

HCV Hepatitis C Virus

EMRO Eastern Mediterranean Region Organization

PMRC Pakistan Medical Research Council

ICT Immuno Chromatography

SDGs Sustainable Development Goals

HBsAg Hepatitis B Antigen

ELIZA Enzyme Linked Immunosorbent Assay

SD Standard Deviation

OR Odds Ratio

Cl Confidence Interval

\section{Declarations}

\section{Ethics approval and consent to participate;}

Ethical Review Committee of Prime Foundation Pakistan, with ERC approval number as Prime/ERC/2019017. 


\section{Consent for publication;}

It was mentioned in the consent form to the parents and the School administration.

\section{Availability of data and materials;}

The datasets used in this study is available within the manuscript as well as uploaded as supplementary files.

\section{Competing interests;}

"The authors declare that they have no competing interests".

\section{Funding;}

No funding of any sort was used in the conduction of this study.

\section{Authors' contributions;}

Jalwa Javed Farooqi; (drjjfarooqi@gmail.com) Substantial contributions to the conception as well as design of the work; acquisition, analysis and interpretation of data for the work with manuscript drafting.

Farhat R Malik; (drfarhatmalik@gmail.com) Supervised, coordinated throughout the research from conception till conduction, revised it critically for intellectual content with final approval of the manuscript for publishing. Agreed to be accountable for all aspects related to this research.

Kanza Javed Farooqi; (kanzajf16@gmail.com) Collected the data and contributed in manuscript writing as well.

Owais Mudassar, (Awais_noor2008@yahoo.com) equally involved from conception, conduction, data collection to manuscript writing.

\section{Acknowledgement;}

All the staff members and the participating patients of this study are greatly appreciated for their precious time, help and collaboration. Above all the silent workers like canteen staff who provided timely tea and snacks during data collection.

\section{References}

1. World Health Organization. Viral Hepatitis: A Hidden Killer Gains Visibility [Internet]. [Cited $1^{\text {st }}$ June, 2020; Updated 2020]. Available from; https://www.who.int/publications/10-year-review/hepatitis/en/

2. Bigna JJ, Kenne AM, Hamroun A, Ndangang MS, Foka AJ, Tounouga DN, et al. Gender development and hepatitis $B$ and $C$ infections among pregnant women in Africa: a systematic review and meta- 
analysis. Infectious Diseases of Poverty; 2019; 8 (1): 16. DOl; https://doi.org/10.1186/s40249-0190526-8

3. Mehmood S, Raza H, Abid F, Saeed N, Rehman HM, Javed S, et al. National prevalence rate of hepatitis B and C in Pakistan and its risk factors. Journal of Public Health; 2019. DOI; https://doi.org/10.1007/s10389-019-01081-5

4. Afsheen Z, Ahmad B, Bashir S. Hospital-visiting pregnant women signal an increased spread of hepatitis $C$ infection in Khyber Pakhtunkhwa region of Pakistan. Virology Journal; 2017; 14 (1):195. DOl; https://doi.org/10.1186/s12985-017-0861-y

5. Ahmad I. Prevalence of Hepatitis B and C Viral Infection Among Pregnant Women in Peshawar, Pakistan. Hepat Mon; 2016 June; 16 (6): e36383-e. DOI: 5812/hepatmon.36383

6. Mabeku LBK, Tchakounte C, Flaurant TT, Etoa FX. Associated Risk Factors and Seroprevalence of Hepatitis B among Pregnant Women Attending Antenatal Clinic in a Rural Setting of Cameroon (Penka-Michel). JAMMR. 2019; 29 (3): 1- 12. DOl; https://doi.org/10.9734/jammr/2019/v29i330072.

7. Sali S, Bashtar R, Alavian SM. Risk Factors in Chronic Hepatitis B Infection: A Case Control Study. Hepatitis Monthly; 2005; 5 (4): 109- 115.

8. Ataei B, Alavian SM, Shahriari-Fard F, Rabiei AA, Safaei A, Rabiei A, et al. A case-control study of risk factors for hepatitis B infection: A regional report among Isfahanian adults. J Res Med Sci; 2019 March 25; 24: 22. DOl; 4103/jrms.JRMS_761_18.

9. Waheed Y, Siddiq M. Elimination of hepatitis from Pakistan by 2030: is it possible? Hepatoma Res2018; 4: 45. 1- 4. DOl; http://dx.doi.org/10.20517/23945079.2018.58.

10. World Health Organization. Global Health Sector Strategies on Viral Hepatitis 2016-2021. Published 22 April 2016 [Online] [Accessed 12 June, 2020] Available from:http://apps.who.int/gb/ebwha/pdf_files/WHA69/A69_32-en.pdf?ua=1.

11. Costa ZB, Machado GC, Avelino MM, Gomes, Filho C, Macedo, Filho JV, Minuzzi AL, et al. Prevalence and risk factors for Hepatitis- $\mathrm{C}$ and HIV infections among pregnant women in Central Brazil. BMC Infect Dis. 2009; 9: 116. doi: 10.1186/1471-2334-9-116.

12. Dortey BA, Anaba EA, Lassey AT, Damale NKR, Maya ET. Seroprevalence of Hepatitis B virus infection and associated factors among pregnant women at Korle-Bu Teaching Hospital, Ghana. PLoS ONE. 2020; 15 (4): DOI: https://doi.org/10.1371/journal.pone.0232208.

13. Barros MMdO, Ronchini KROdM, Soares RLS. HEPATITIS B AND C IN PREGNANT WOMEN ATTENDED BY A PRENATAL PROGRAM IN AN UNIVERSITARY HOSPITAL IN RIO DE JANEIRO, BRAZIL: RETROSPECTIVE STUDY OF SEROPREVALENCE SCREENING. Arquivos de Gastroenterologia. 2018; 55: 267- 273. DOI: https://doi.org/10.1590/s0004-2803.201800000-68.

14. Talaat M, Radwan E, El-Sayed N, Ismael T, Hajjeh R, Mahoney FJ. Case-control study to evaluate risk factors for acute hepatitis B virus infection in Egypt. EMHJ 2010;16 (1): 4-9.

15. Akhtar H, Badshah Y, Akhtar S, Hasan F, Faisal M, Zaidi NSS et al. Prevalence of hepatitis B and hepatitis $C$ Virus infections among male to female (MFT) transgenders in Rawalpindi (Pakistan). Adv. Life Sci- International Quarterly Journal of Biological Sciences 2018; 5 (2): 46-55. 
16. Mustapha GU, Ibrahim A, Balogun MS, Umeokonkwo CD, Mamman Al. Seroprevalence of hepatitis B virus among antenatal clinic attendees in Gamawa Local Government Area, Bauchi State, Nigeria. BMC Infectious Diseases. 2020; 20 (1): 194. DOI: https://doi.org/10.1186/s12879-020-4863-9.

17. Fouelifack FY, Fouedjio JH, Fouogue JT, Fouelifa LD. Seroprevalences and Correlates of Hepatitis B and C Among Cameroonian Pregnant Women. Clinical Medicine Insights: Reproductive Health. 2018; 12: DOI: https://doi.org/10.1177/1179558118770671

18. Khattak ST, Ali Marwat M, Khattak lu, Khan TM, Naheed T. Comparison of frequency of hepatitis B and hepatitis $\mathrm{C}$ in pregnant women in urban and rural area of district Swat. $J$ Ayub Med Coll Abbottabad. 2009; 21 (2): 12- 15.

19. Latif R, Rafique S, Ashfaq M, Javeed S, Yasmin T, Kalsoom Z et al; Frequency of Hepatitis B \& C and Related Risk Factors in Pregnant Women. PJMHS. 2016; 10 (4); 1126- 1128.

20. Sheikh SM. Hepatitis B \& C: Value of Universal Antenatal Screening. CPSP. 2009; 19 (3); 179- 182.

\section{Tables}

Table 1; Demographic Characteristics of Study Participants $(n=42)$ 


\begin{tabular}{|c|c|c|c|}
\hline SNO & VARIABLES & $\begin{array}{l}\text { CASES }(n=21) \\
n(\%)\end{array}$ & $\begin{array}{l}\text { CONTROLS }(n=21) \\
n(\%)\end{array}$ \\
\hline 1 & Age in years (mean $\pm S D$ ) & $37( \pm 9)$ & $28( \pm 6)$ \\
\hline \multirow[t]{3}{*}{2} & Residency & & \\
\hline & Urban & $7(33.3)$ & $14(66.6)$ \\
\hline & Rural & $14(66.6)$ & 7 (33.3) \\
\hline 3 & Marital status (married) & $21(100)$ & $21(100)$ \\
\hline \multirow[t]{3}{*}{4} & Occupational status & & \\
\hline & Working & $2(9.5)$ & $2(9.52)$ \\
\hline & Housewife & $19(90.5)$ & $19(90.4)$ \\
\hline \multirow[t]{4}{*}{5} & Educational level & & \\
\hline & No formal education & $17(81.0)$ & $12(57.1)$ \\
\hline & Primary level & $3(14.3)$ & $7(33.3)$ \\
\hline & Secondary level & $1(4.8)$ & $2(9.52)$ \\
\hline \multirow[t]{5}{*}{6} & Gestational age & & \\
\hline & First trimester & $1(4.8)$ & - \\
\hline & Second trimester & $4(19)$ & $3(14.2)$ \\
\hline & Third trimester & $10(47.6)$ & 18 (85.7) \\
\hline & Postpartum within 40 days & $6(28.5)$ & - \\
\hline \multirow[t]{3}{*}{7} & Parity & & \\
\hline & Primi-Para & $4(19)$ & $5(23.8)$ \\
\hline & Multi-Para & $17(80.9)$ & $16(76.1)$ \\
\hline
\end{tabular}

Table 2; Analysis of the Study Variables 


\begin{tabular}{|lllll|}
\hline S NO & VARIABLES & OR & $95 \% \mathrm{Cl}$ & P-Value \\
\hline 1 & Parity & 0.753 & $0.171-3.312$ & 0.7 \\
\hline 2 & Delivery àHome & $4.267^{*}$ & $1.134-16.050$ & 0.02 \\
\hline 3 & Delivery à Hospital & 0.100 & $0.01-0.906$ & 0.01 \\
\hline 4 & Normal Vaginal Delivery & $1.969^{*}$ & $0.518-7.488$ & 0.3 \\
\hline 5 & Caesarean Section & 0.708 & $0.138-3.641$ & 0.6 \\
\hline 6 & Injection à Market & 0.821 & $0.239-2.810$ & 0.53 \\
\hline 7 & Injection à Hospital & $1.477^{*}$ & $0.432-5.046$ & 0.75 \\
\hline 8 & Abortion History & $1.231^{*}$ & $0.348-4.358$ & 0.7 \\
\hline 9 & E/C Done & 0.337 & $0.057-1.977$ & 0.2 \\
\hline
\end{tabular}

Note; OR= Odds Ratio; $\mathrm{Cl}=$ Confidence Interval.

*Indicates $\mathrm{OR}>1$ (Exposure associated with higher odds of outcome); however, rest are $\mathrm{OR}<1$ meaning exposure associated with lower odds of outcome.

\section{Graph}

Graph 1 can be found in the Supplemental Files section

\section{Supplementary Files}

This is a list of supplementary files associated with this preprint. Click to download.

- Graph1.JPG 